Pesq. Vet. Bras. 30(3):267-276, março 2010

\title{
Doenças do sistema nervoso de bovinos no semiárido nordestino ${ }^{1}$
}

\author{
Glauco J.N. Galiza², Maria L.C.R. Silva², Antônio F.M. Dantas², Sara V.D. \\ Simões $^{2}$ e Franklin Riet-Correa ${ }^{2^{*}}$
}

\begin{abstract}
Galiza G.J.N., Silva M.L.C.R, Dantas A.F.M., Simões S.V.D. \& Riet-Correa F. 2010. [Diseases of the nervous system of cattle in the semiarid of Northeastern Brazil.] Doenças do sistema nervoso de bovinos no semiárido nordestino. Pesquisa Veterinária Brasileira 30(3):267-276. Hospital Veterinário, CSTR, Campus de Patos da Universidade Federal de Campina Grande, Patos, PB 58700-000, Brazil. E-mail: franklin.riet@pq.cnpq.br

Diseases of the nervous system of cattle in the semiarid region of northeastern Brazil were evaluated by a retrospective study of 411 cattle necropsies performed in the Veterinary Hospital of the Federal University of Campina Grande, Patos, Paraíba, from January 2000 to December 2008. Of the 411 cases analyzed, 139 (33.81\%) were from cattle that presented nervous signs and the records were reviewed to determine the epidemiological, clinical, and macroscopic and histologic main features. Diagnosis was inconclusive in 28 cases $(20.14 \%)$. In cases with diagnosis the main diseases were rabies $(48.7 \%$ of the cases with nervous signs), brain abscesses $(7.2 \%)$ including three cases of pituitary abscesses, malignant catarrhal fever $(6.3 \%)$, botulism $(6.3 \%)$, congenital malformations $(4.5 \%)$, trauma $(4.5 \%)$, tuberculosis $(2.7 \%)$, tetanus $(2.7 \%)$, infection by bovine hervesvirus-5 (2.7\%), non-suppurative encephalomyelitis $(2.7 \%)$, intoxication by Prosopis juliflora (2.7\%), congenital status spongiosus of unknown etiology (1.8\%), and polioencephalomalacia (1.8\%). Other diseases diagnosed only once $(0.9 \%)$ were cryptococcosis, listeriosis, thromboembolic encephalitis, lymphosarcoma, trypanossomiasis, and babesiosis by Babesia bovis.
\end{abstract}

INDEX TERMS: Diseases of cattle, botulism, brain abscess, malignant catarrhal fever, pituitary abscess, polioencephalomalacia, rabies, tuberculosis.

RESUMO.- Para determinar as doenças que ocorrem no sistema nervoso de bovinos no semiárido nordestino, foi realizado um estudo retrospectivo em 411 necropsias de bovinos realizadas no Hospital Veterinário da Universidade Federal de Campina Grande, Patos, Paraíba, entre janeiro de 2000 a dezembro de 2008. Dos 411 casos analisados $139(33,81 \%)$ apresentaram alterações clínicas do sistema nervoso e as fichas foram revisadas para determinar os principais achados referentes à epidemiologia, aos sinais clínicos e às alterações macroscópicas e microscópicas. Em 28 (20,14\%) casos o diagnóstico foi inconclusivo. As principais enfermidades foram raiva (48,7\% dos casos com sinais nervosos), abscessos cere-

\footnotetext{
${ }^{1}$ Recebido em 9 de outubro de 2009.

Aceito para publicação em 13 de dezembro de 2009.

${ }^{2}$ Centro de Saúde e Tecnologia Rural (CSTR), Universidade Federal de Campina Grande (UFCG), Campus de Patos, 58700-000 Patos, PB, Brasil. *Autor para correspondência: franklin.riet@pq.cnpq.br
}

brais $(7,2 \%)$ incluindo três casos de abscesso da pituitária, febre catarral maligna $(6,3 \%)$, botulismo $(6,3 \%)$, alterações congênitas $(4,5 \%)$, traumatismo $(4,5 \%)$, tuberculose $(2,7 \%)$, tétano $(2,7 \%)$, infecção por herpesvírus bovino-5 $(2,7 \%)$, encefalomielite não supurativa $(2,7 \%)$, intoxicação por Prosopis juliflora (2,7\%), status spongiosus congênito de causa desconhecida $(1,8 \%)$ e polioencefalomalacia $(1,8 \%)$. Outras doenças diagnosticadas numa única oportunidade $(0,9 \%)$ foram criptococose, listeriose, encefalite tromboembólica, linfossarcoma, tripanossomíase e babesiose por Babesia bovis.

TERMOS DE INDEXAÇÃO: Doenças de bovinos, botulismo, abscesso cerebral, febre catarral maligna, abscesso de pituitária, polioencefalomalacia, raiva, tuberculose.

\section{INTRODUÇÃO}

Os distúrbios do sistema nervoso (SN) em bovinos abrangem um grupo de enfermidades responsáveis por impor- 
tantes perdas econômicas em todo o mundo. De 1986 a 1995, o botulismo causou a morte de mais de 6 milhões de bovinos adultos no Brasil (Dutra 2001). A raiva é uma virose importante para a pecuária e para a saúde pública no Brasil, estima-se que as perdas anuais de bovinos por raiva sejam de aproximadamente 850.000 cabeças, que equivalem aproximadamente a 17 milhões de dólares (Lima et al. 2005).

A importância do estudo das enfermidades do SN aumentou desde o aparecimento da encefalopatia espongiforme dos bovinos (BSE), em meados da década de 1980 (Wells et al. 1987). Sua importância política, econômica, social e de saúde pública foi realçada quando o surgimento de uma nova variante da doença humana CreutzfeldtJacob (vCJD) relacionada à BSE (Will et al. 1996). Por causa disso, autoridades sanitárias internacionais estão solicitando dos países exportadores de carne, como é o caso do Brasil, que apresentem evidências de que seus rebanhos são livres de BSE. Isso equivale dizer que os países devem estar capacitados a identificar as outras doenças que afetam o sistema nervoso central de bovinos, mesmo na ausência de casos de BSE (Sanches et al. 2000).

O Hospital Veterinário do Centro de Saúde e Tecnologia Rural da Universidade Federal de Campina Grande (HVCSTR-UFCG) vem realizando diagnósticos sistemáticos das doenças dos animais na sua área de influência, que abrange principalmente o semiárido da Paraíba, Pernambuco e Rio Grande do Norte. O objetivo desse trabalho é determinar as principais doenças do SN de bovinos diagnosticados no Laboratório de Patologia Animal da UFCG no período de janeiro de 2000 a dezembro de 2008.

\section{MATERIAL E MÉTODOS}

Foram revisadas todas as fichas de necropsias de bovinos diagnosticados com alterações nervosas no Laboratório de Patologia Animal da Universidade Federal de Campina Grande, Campus de Patos, Paraíba, no período de janeiro de 2000 a dezembro de 2008. Avaliaram-se os dados epidemiológicos (raça, sexo, idade, procedência e época de ocorrência da doença), sinais clínicos, curso clínico e alterações macroscópicas e microscópicas descritas nas fichas de necropsias. Depois da análise das fichas foram identificadas e revisadas as lesões histológicas de todos os casos. Cada diagnóstico equivale à ocorrência de doença em uma propriedade, podendo se referir tanto a um único animal acometido quanto a surtos. Os materiais provenientes de necropsias foram fixados em formol a $10 \%$, e em seguida encaminhados para diafanização e embebição em parafina, sendo depois cortados em secções de $5 \mu \mathrm{m}$ e corados com hematoxilina e eosina. Utilizaram-se também colorações especiais como a de Gomori e o ácido periódico de Schiff (PAS) para visualização de fungos. Em dois casos de tuberculose utilizou-se a coloração de Ziehl-Neelsen e foram enviados fragmentos de encéfalo e medula espinhal para o Laboratório de Patologia Veterinária da Universidade Federal do Rio Grande do Sul, onde foram submetidos ao teste de imuno-histoquímica com anticorpo policlonal anti-Mycobacterium spp. na diluição de 1:200. Diaminobenzidina ${ }^{3}(D A B)$ foi o cromógeno utilizado. Nos casos suspeitos de raiva foram reali- zados imunofluorescência e inoculação intracranial em camundongos para confirmar o diagnóstico. Em um caso suspeito de raiva foi realizado exame de imuno-histoquímica utilizando anticorpo policlonal antirribonucleoproteína (rabies polyclonal DFA reagent ${ }^{4}$ ) na diluição de 1:1000, no Laboratório de Patologia Veterinária da Universidade Federal de Santa Maria.

\section{RESULTADOS}

No período estudado foram examinadas 411 fichas de bovinos necropsiados. Em 139 (33,81\%) havia histórico de alterações clínicas no SN e em 111 foi realizado o diagnóstico (Quadro 1). Em 23 casos (16,54\% de 139) não foram observadas alterações que justificassem os sinais

\section{Quadro 1. Diagnósticos realizados em 111 bovinos com sinais clínicos de alterações nervosas, atendidos no Hospital Veterinário do Centro de Saúde e Tecnologia Rural da Universidade Federal de Campina Grande, \\ Patos, PB, no período de janeiro de 2000 a dezembro de} 2008

\begin{tabular}{lcc}
\hline \multicolumn{1}{c}{ Diagnósticos } & $\begin{array}{c}\text { Números de } \\
\text { casos/surtos }\end{array}$ & $\%$ \\
\hline Raiva & 54 & 48,7 \\
Abscessos no sistema nervoso & 8 & 7,2 \\
FCM & 7 & 6,3 \\
Botulismo & 7 & 6,3 \\
Traumatismos & 5 & 4,5 \\
Alterações congênitas & 5 & 4,5 \\
Encefalite e mielite não supurativa & 3 & 2,7 \\
Intoxicação por Prosopis juliflora & 3 & 2,7 \\
Tuberculose & 3 & 2,7 \\
Encefalite por herpesvírus bovino tipo 5a & 3 & 2,7 \\
Tétano & 3 & 2,7 \\
Status spongiosus & 2 & 1,8 \\
Polioencefalomalacia & 2 & 1,8 \\
Criptococose & 1 & 0,9 \\
Listeriose & 1 & 0,9 \\
Encefalite embólica bacteriana & 1 & 0,9 \\
Neoplasia & 1 & 0,9 \\
Tripanossomíase & 1 & 0,9 \\
Babesiose & 1 & 0,9 \\
Total & 111 & 100
\end{tabular}

a Diagnóstico baseado na lesão histológica.

clínicos e em 5 casos (3,59\% de 139) o material analisado encontrava-se impróprio para o exame histológico.

\section{Doenças víricas}

Sessenta e quatro casos foram associados a doenças atribuídas a vírus, sendo 54 de raiva. Vinte e quatro desses foram descritos por Lima et al. (2005). Dos 30 casos restantes, 24 foram positivos para a IFD e IIC e na histologia apresentaram meningoecefalite linfoplasmocitária e corpúsculos de inclusão. Dois casos positivos para IFD e IIC apresentaram meningoencefalite linfoplasmocitária, sem corpúsculos de inclusão. Três casos nos que

\footnotetext{
${ }^{3}$ SIGMA, D-5637 Sigma-Aldrich, 3050 Spruce Street, St Louis, MO 63103, USA, http://www.sigma-aldrich.com

${ }^{4}$ Chemicon $₫$ International Catalog number 5199, 28820 Single Oak Drive, Temecula, California 92590, USA, www.chemicon.com
} 


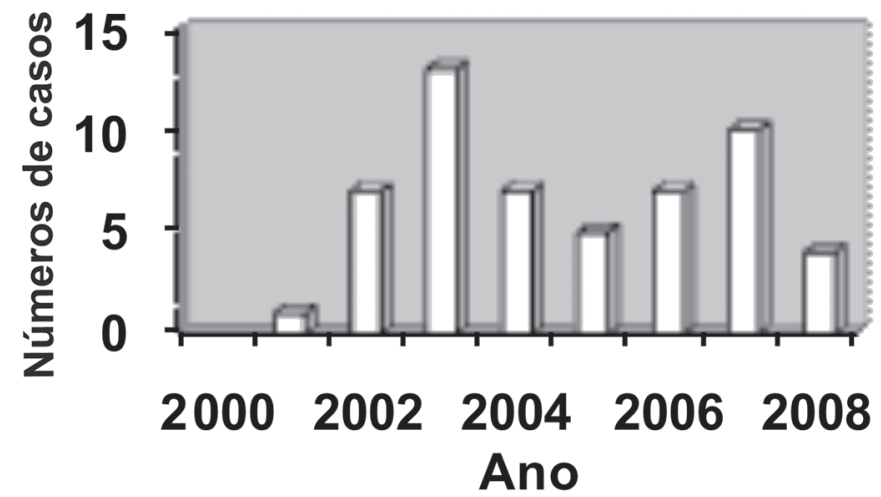

Fig.1. Distribuição anual dos casos de raiva diagnosticados pelo Hospital Veterinário da Universidade Federal de Campina Grande, entre os anos de 2000 e 2008.

não feito histologia foram positivos na IFD e IIC. O caso restante que apresentava meningoencefalite linfoplasmocitária, com ausência de corpúsculos de inclusão, no qual não foi feita IFD e IIC, foi positivo para raiva na imunohistoquímica. Os achados histopatológicos caracterizavam-se pela presença de infiltrado inflamatório mononuclear, predominantemente constituído por linfócitos, plasmócitos e alguns macrófagos, formando manguitos perivasculares. Nas leptomeninges também havia infiltrado inflamatório mononuclear. Os corpúsculos de inclusão foram mais freqüentes no cerebelo, ponte e no tubérculo quadrigêmeo anterior. Os principais sinais clínicos eram incoordenação e paralisia dos membros pélvicos evoluindo para os torácicos, decúbito esternal e lateral, salivação, perda da sensibilidade, paralisia da cauda, diminuição do reflexo anal, trismo mandibular, cegueira, opistótono, movimentos de pedalagem e dilatação das pupilas. A evolução clínica variou de dois a oito dias. A Figura 1 mostra a distribuição dos casos de raiva em cada ano.

Foram diagnosticados sete casos de febre catarral maligna (FCM). A alteração histopatológica característica observada no sistema nervoso central (SNC) era uma vasculite, composta de infiltrado inflamatório mononuclear e degeneração hialina das paredes dos vasos. Havia vasculite nos demais órgãos juntamente com a presença de úlceras na cavidade oral, língua e esôfago, que contribuíram para confirmar o diagnóstico. Em três casos foi relatado que os bovinos pastavam junto com ovinos. Os principais sinais clínicos descritos foram: congestão bilateral de conjuntivas, salivação, opacidade de córnea, cegueira e lacrimejamento bilateral, febre, secreção nasal catarral, úlceras na cavidade oral e narinas, torneio e anorexia. Cinco desses casos foram descritos anteriormente (Macêdo et al. 2007).

Três casos foram diagnosticados como meningoencefalite não supurativa associada a malacia. Nesses casos, a idade dos bovinos variarou de 18 a 24 meses com evolução clínica entre quatro a nove dias. Os sinais clínicos caracterizavam-se por cegueira, pressão da cabeça contra objetos, andar em círculos, incoordenação, trismo mandibular, paralisia de língua, arrastar de pinças e diminuição da sensibilidade da face. Macroscopicamente no encéfalo foram observadas cavitações com conteúdo gelatinoso e amarelado no córtex frontal e córtex temporal. Um caso apresentava lesões semelhantes, simétricas, no núcleo caudato e nos giro do para-hipocampo. Em um caso observou-se também hemorragia na região ventral do tronco encefálico, cerebelo e porção inicial da medula espinhal. Histologicamente verificaram-se áreas multifocais de malácia com microcavitações e numerosas células gitter, neurônios vermelhos, neurôniofagia e gliose associadas à vacuolizações da neurópila, edema e hemorragia adjacente. Havia manguitos perivasculares mononucleares, infiltrado de linfócitos e plasmócitos na neurópila e nas leptomeninges e vasculite e tumefação endotelial, principalmente no córtex frontal e núcleo caudato. Lesões de meningoencefalite, mais discretas que no córtex, foram observadas também no tronco encefálico. Com base nas lesões histológicas foi realizado diagnóstico de infecção por herpesvírus bovino tipo 5 .

\section{Doenças causadas por fungos}

Foi diagnosticado um caso de criptococose em um bovino macho de cinco anos de idade da raça Pardo-Suíço, que apresentava inapetência, depressão, pressão da cabeça contra obstáculos, torneio, dismetria, ataxia, evoluindo para decúbito lateral movimentos de pedalagem, nistagmo e ausência do reflexo anal e de flexão dos membros. Na necropsia encontrou-se uma camada de fibrina envolvendo a medula oblonga e os ventrículos laterais, além de engrossamento da meninge na base do crânio. No encéfalo foi observada marcada assimetria com aumento de volume do lado esquerdo e cavidades císticas com material translúcido e gelatinoso. Havia múltiplas cavitações nos núcleos da base e duas lesões simétricas afetando o córtex frontal, lóbulo piriforme, córtex occipital, parietal, lobo do hipocampo e parte inferior do córtex temporal. Havia hidrocefalia e assimetria nos ventrículos laterais. $\mathrm{Na}$ histopatologia observou-se meningoencefalite granulomatosa, multifocal com áreas císticas contendo leveduras com aspecto de bolhas de sabão. As leveduras foram melhor observadas nas colorações de Gomori e PAS. O agente foi identificado por imuno-histoquímica como Cryptococcus neoformans var. grubii.

\section{Doenças bacterianas}

As doenças atribuídas a agentes bacterianos somaram vinte e três casos. Oito casos de abscessos no SN foram diagnosticados, incluindo três casos de abscesso da pituitária que ocorreram em animais jovens com idade de 30 dias (Bovino 1), três meses (Bovino 2) e seis meses (Bovino 3). No Bovino 1 os sinais clínicos foram edema na região do chanfro e decúbito lateral. O Bovino 2 apresentou apatia, incoordenação, diminuição dos reflexos, pressão da cabeça contra obstáculos, protrusão do olho esquerdo, arqueamento do dorso, andar em círculos, hipersensibilidade, hiperalgesia, decúbito lateral, 
salivação e movimentos de pedalagem. No Bovino 3 observou-se dispnéia, anorexia, salivação espumosa, retração do globo ocular, diminuição da acuidade visual, dismetria, tremores musculares, decúbito lateral, nistagmo, estrabismo ventro-medial e flacidez de mandíbula. $\mathrm{Na}$ necropsia dos três casos observou-se exsudato purulento na superfície das leptomeninges estendendo-se do tálamo até porção final do tronco encefálico e cerebelo e aumento de volume da região da hipófise de consistência flutuante. O Bovino 2 apresentava também dilatação dos ventrículos e herniação do cerebelo. Histologicamente no abscesso havia infiltrado inflamatório neutrofílico e restos celulares envolvido por tecido conjuntivo, e infiltrado inflamatório neutrofílico com deposição de fibrina nas leptomeninges. Nos Bovinos 1 e 3, os abscessos eram laterais à hipófise e no Bovino 2 o abscesso estava localizado no centro da hipófise. No Bovino 3, o animal tinha sido submetido ao uso de tabuleta de desmame e no Bovino 1 observou-se uma lesão penetrante no focinho. No Bovino 2 não foi relatado histórico de desmame por tabuleta, não observando-se nenhuma lesão nas narinas.

Dois casos de retículo pericardite traumática (RPCT) com abscessos no SN, foram observados em um animal com 11 meses de idade (Bovino 4) e outro com oito anos de idade (Bovino 5). O Bovino 4 apresentou apatia, debilidade muscular e decúbito lateral. O Bovino 5 não apresentou alterações neurológicas. Macroscopicamente nos dois animais observou-se presença de corpo estranho (arame) na parede do coração e microabscessos nas meninges, tálamo e substância branca sub-cortical. Histologicamente, em ambos os casos de RPCT, as lesões do SN caracterizavam-se por áreas multifocais de abscessos com necrose central e colônias bacterianas levemente basofílicas, circundadas por infiltrado inflamatório neutrofílico envolvido por tecido conjuntivo.

Abscesso no SN foi observado também num caso de retículo peritonite traumática (RPT). $\mathrm{O}$ animal apresentou anorexia andar em círculos, pressão da cabeça contra obstáculos, decúbito esternal, depressão, nistagmo, estrabismo, diminuição do reflexo corneal e relaxamento de mandíbula. Macroscopicamente observou-se a presença de arame na parede do retículo. O encéfalo apresentava amolecimento bilateral dos hemisférios, dilatação dos ventrículos laterais e presença de abscesso no núcleo da base, plexo coróide e tálamo. Histologicamente observouse vasculite e infiltrado inflamatório mononuclear no tronco encefálico. Na medula havia meningite com infiltrado inflamatório mono e polimorfonuclear. Na neurópila observaram-se extensas áreas de infiltrado inflamatório misto e necrose.

Um caso de abscesso cerebelar foi observado em um animal que apresentou dismetria, extensão da cabeça e hiperexcitabilidade. Macroscopicamente o cerebelo apresentou área focal de $3 \mathrm{~cm}$ de diâmetro com material caseoso envolvido por uma cápsula. Histologicamente observaram-se áreas de necrose com infiltrado neutrofílico e histioplasmocitário e proliferação de tecido fibroso.
Em um caso de compressão medular o animal apresentou paraplegia e decúbito permanente. Macroscopicamente observou-se um abscesso, de $1,5 \mathrm{~cm}$ de diâmetro, comprimindo a medula entre a oitava (T8) e nona (T9) vértebra torácica com exostose da T8.

Sete surtos de botulismo foram diagnosticados. Os sinais clínicos foram decúbito esternal permanente, ausência do reflexo anal, paralisia flácida dos membros e cauda, salivação, relaxamento de mandíbula e facilidade na exposição da língua. O diagnóstico foi realizado com base nos sinais clínicos, epidemiologia e ausência de lesões no SN. Quatro casos de botulismo estavam associados ao consumo de cama de frango e três à ingestão de água contaminada. Nos casos de botulismo associados ao consumo de cama de frango a mortalidade variou de 10,8 a $33 \%$, enquanto nos casos de botulismo hídrico a mortalidade variou de 7,5 a $37,5 \%$.

Tuberculose foi diagnosticada em três casos: um em bovino adulto da raça Sindhi (Bovino 6); outro em um bovino de um ano e três meses da raça Pardo-Suíço (Bovino 7); e um outro em um mestiço de Holandês de nove anos (Bovino 8). Os sinais clínicos do Bovino 6, que reagiu positivo a tuberculinização, caracterizavamse por tosse, perda de peso progressiva, anorexia e aumento de tamanho dos linfonodos. O Bovino 7 apresentava incoordenação, debilidade e diminuição da sensibilidade dos membros pélvicos, postura de cão sentado (Fig.2A) e incontinência urinária. Esse animal reagiu negativamente à tuberculinização. O líquido cefaloraquideano apresentava numerosos linfócitos. O Bovino 8 era positivo para brucelose e foi eutanasiado sem apresentar alterações clínicas aparentes. Macroscopicamente nos Bovinos 6 e 8 as leptomeninges estavam difusamente espessadas e firmes (Fig.2B e C). No Bovino 7 havia, no interior dos ventrículos laterais, projeções que ao corte evidenciavam mineralização; na medula, além de lesões nas meninges semelhantes às descritas anteriormente, observavam-se áreas esbranquiçadas irregulares de até $0,5 \mathrm{~cm}$ de diâmetro afetando a substância branca e cinzenta da medula (Fig.2D). Os pulmões dos Bovinos $6 \mathrm{e}$ 7 apresentavam múltiplos nódulos amarelados irregulares e caseosos ao corte. Os linfonodos estavam aumentados e a superfície de corte amarelada e caseosa. No Bovino 6, o rim esquerdo continha múltiplos nódulos caseosos na superfície subcapsular que adentrava a superfície de corte. Histologicamente os Bovinos 6 e 8 apresentavam meningite granulomatosa difusa acentuada e o Bovino 7 meningite e encefalomielite granulomatosa difusa acentuada, caracterizadas por áreas de necrose central com mineralização, circundadas por infiltrado inflamatório constituído por macrófagos epitelióides, células gigantes tipo Langhans, linfócitos e plasmócitos envolvidos por tecido fibroso. No pulmão, linfonodos e rim, havia granulomas multifocais típicos de tuberculose. Foram observados bacilos ácido-alcool resistentes em células gigantes tipo Langhans e macrófagos epitelióides. Os Bovinos 6 e 7, nos que foi realizado 


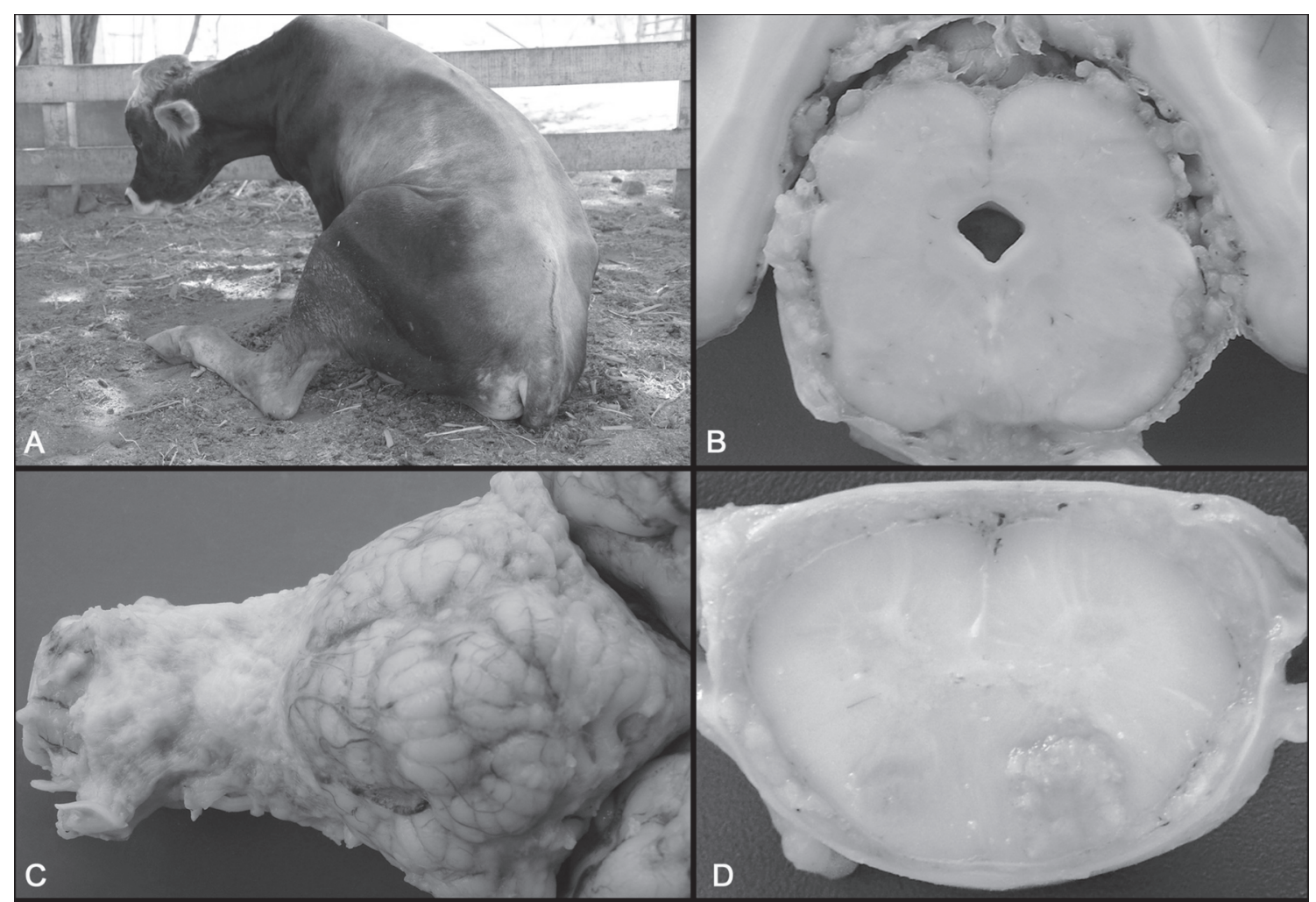

Fig.2. Tuberculose. Bovino 7. (A) Observa-se postura de cão sentado. (B,C) As leptomeninges apresentam-se difusamente espessadas, firmes e com aspecto granular. (D) Medula com lesões esbranquiçadas irregulares afetando a substância branca e cinzenta.

imuno-histoquímica, apresentaram marcação positiva para Mycobacterium spp.

Três casos de tétano foram diagnosticados. Um em bezerro de trinta dias de idade que apresentou espasticidade muscular e trismo mandibular. Nos dois outros casos os bezerros apresentaram, logo após o nascimento, espasticidade dos quatro membros e opistótono (Fig.3). Nas necropsias e nos exames histopatológicos não foram observadas alterações significativas.

Um caso de encefalite tromboembólica bacteriana foi

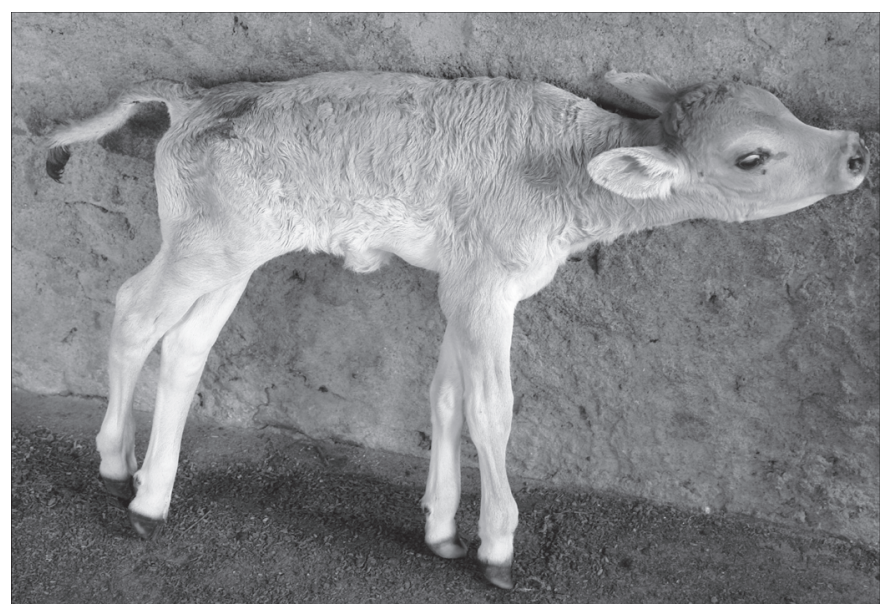

Fig.3. Bovino com tétano apresentando espasticidade dos quatro membros e opistótono, logo após o nascimento. diagnosticado em um animal de dois anos de idade. Os sinais clínicos observados foram de irritação, andar cambaleante, evoluindo para paralisia dos membros posteriores e anteriores com prostação. A evolução da doença foi de quatro dias. Microscopicamente foram observadas áreas multifocais de malácia com colônias bacterianas basofílicas e infiltrado inflamatório de polimorfonucleares na neurópila e na luz de vasos da substância cinzenta e branca do córtex cerebral e na camada granular do cerebelo. Nas leptomeninges do cerebelo observou-se a formação de trombos nos vasos.

Lesões características de listeriose foram observadas em um bovino de cinco anos de idade. Os sinais clínicos observados foram anorexia, andar cambaleante, cabeça voltada para o flanco, decúbito esternal, nistagmo, estrabismo, paralisia da língua, reflexo anal diminuído e paralisia da cauda. Microscopicamente observaram-se manguitos perivasculares de células mono e polimorfonucleares, microabscessos no bulbo e infiltrado inflamatório misto nas leptomeninges do córtex occipital e cerebelo.

\section{Doenças tóxicas}

Foram observados três casos de intoxicação por Prosopis juliflora (algaroba). Os animais tinham oito, três e dois anos de idade e apresentaram desvio lateral da cabeça durante a mastigação (Fig.4A), magreza acentuada, flacidez de mandíbula, salivação, protusão da língua 


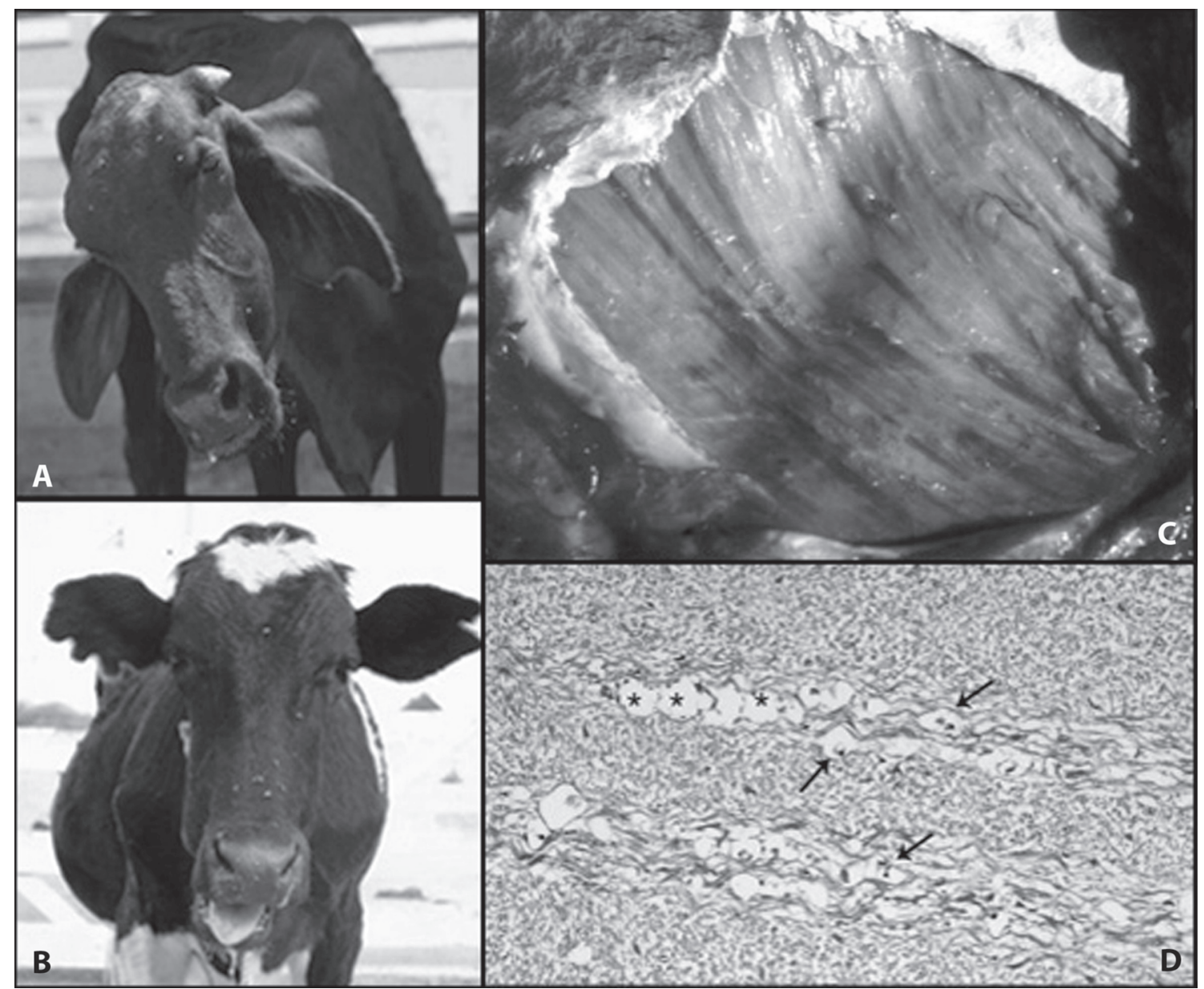

Fig.4. Intoxicação por vagens de Prosopis juliflora em bovinos. (A) Bovino com desvio da cabeça ("cara torta") para manter o alimento na boca. (B) Bovino com salivação, protrusão da língua e atrofia dos músculos masseteres. (C) Músculo masseter de aspecto amarelado em conseqüência da atrofia por desnervação. (D) Tronco encefálico. Observam-se as raízes do nervo trigêmeo com degeneração Walleriana, caracterizada por vacúolos, em cadeia (asteriscos), ocasionalmente contendo restos de axônios ou macrófagos (setas). HE, obj.20x.

(Fig.4B), dificuldade em apreender os alimentos e atrofia do músculo masseter. Na necropsia os músculos da mastigação (masseter, temporal, bucinador e pterigóide medial) estavam atrofiados e com uma coloração amarelada (Fig.4C). Na histologia observaram-se lesões nos núcleos motor do nervo trigêmio, dos nervos facial, hipoglosso e oculomotor caracterizadas por discreta vacuolização do pericário, com deslocamento de núcleo sem definição da cromatina, neurônios fantasma, esferóides axonais e degeneração Walleriana nas raízes de nervos cranianos (Fig.4D). As fibras musculares apresentavamse delgadas com formato triangular, caracterizando uma atrofia por desnervação, com substituição das fibras musculares por tecido fibroso e gordura.

\section{Malformações}

Cinco casos de malformações congênitas foram observados, incluindo hidrocefalia, hipoplasia dos hemisférios cerebelares, escoliose, espinha bífida, artrogripose e gêmeos siameses. Dois casos de malformação na colu- na vertebral estavam associados à artrogripose, sendo que um apresentava escoliose e o outro caso espinha bífida. No caso da hidrocefalia observou-se ausência do telencéfalo e dilatação do terceiro ventrículo por líquor. $\mathrm{Na}$ hipoplasia cerebelar o animal apresentou cegueira, decúbito lateral e opistótono. Nesse caso ocorreu hipoplasia dos hemisférios cerebelares, ausência do verme cerebelar e véu medular, dilatação dos ventrículos laterais e terceiro ventrículo, formação incompleta da fossa romboíde (assoalho do quarto ventrículo) e dos colículos caudais. Nos gêmeos siameses os animais eram ligados pela região do tórax e apresentavam medula espinhal dupla, cauda bífida, cinco membros, sendo um atrofiado e malformado na região da cartilagem xifóide, órgãos internos duplicados (pulmão, coração, pré-estômagos, abomaso e fígado) e região cervical e cefálica sem alterações.

\section{Doenças traumáticas}

Cinco casos foram diagnosticados como sendo decor- 
rentes de traumas. Em quatro casos de traumatismo craniano, dois ocorreram em bezerros com idade de oito dias e cinco meses, os outros dois casos ocorreram em bovinos com 2 e 5 anos de idade. Os animais foram encontrados mortos no curral sem que anteriormente apresentassem nenhuma alteração clínica. Na necropsia foram observadas áreas de hemorragia e coágulo no encéfalo. Em um caso de fraturas de vértebras sacrais, um bovino de seis anos de idade apresentou debilidade dos membros posteriores com emboletamento e secreção purulenta na vulva.

\section{Doenças parasitárias}

Dois casos de doenças parasitárias foram diagnosticados, sendo um surto de tripanossomíase e um caso de babesiose por Babesia bovis. O surto de tripanossomíase foi descrito anteriormente (Batista et al. 2007, 2008). O caso de babesiose ocorreu, em julho de 2006, em um bovino de 2 anos de idade que apresentou tremores musculares, ataxia, dismetria e mucosas ictéricas. Na necropsia observou-se icterícia generalizada e moderada, fígado marrom alaranjado, discretamente aumentado e vesícula biliar distendida e com hemorragia na parede e petéquias e equimoses no subcutâneo e músculo cardíaco (subepicárdio e subendocárdio). Os rins apresentavam coloração enegrecida e bexiga repleta de urina avermeIhada escura. O córtex cerebral apresentava-se difusamente avermelhado. Na microscopia do encéfalo foi observado congestão, edema perivascular e pequenas hemorragias no córtex. Nos esfregaços de cérebro foram observados parasitos dentro dos eritrócitos com as características de $B$. bovis.

\section{Outras doenças}

Foram diagnosticados dois casos de polioencefalomalacia. Um caso ocorreu em um bovino de seis meses de idade no mês de outubro (Bovino 9) e o outro ocorreu em um bovino de dois meses de idade no mês de julho (Bovino 10). O Bovino 9 apresentou, subitamente, sintomatologia nervosa com diminuição do tônus lingual que ao ser tracionada ficava exposta, cegueira, estrabismo, bruxismo, incoordenação, pressão da cabeça contra obstáculos, decúbito lateral e movimentos de pedalagem. Os sinais do Bovino 10 caracterizaram-se por relaxamento de mandíbula, depressão, reflexo palpebral e sensibilidade da face diminuídos, ausência do reflexo de ameaça e decúbito lateral. Na necropsia do Bovino 9 observou-se hemorragia na piamater e áreas de amolecimento no córtex cerebral. O Bovino 10 apresentou amolecimento do córtex com desprendimento entre as substâncias cinzenta e branca. As lesões histológicas do córtex caracterizavam-se por áreas extensas de necrose com infiltrado de células gitter, tumefação endotelial, neurônios vermelhos, astrócitos reativos, esferóides axonais, hemorragia nas leptomeninges e edema com separação da substância cinzenta e branca do encéfalo. Lesões histológicas semelhantes foram observadas também no tálamo, colículo caudal e núcleos da base.
Foram realizados dois diagnósticos de status spongiosus do sistema nervoso central. Um surto acometeu dois bezerros da raça Sindhi e foi descrito por Guedes et al. (2006). Outro caso com lesões difusas de status spongiosus da substância branca do SNC ocorreu em um bezerro de cinco meses de idade da raça Guzerá. Nesse caso o fígado estava difusamente pálido e apresentando severa vacuolização do citoplasma de hepatócitos.

Três casos de encefalite não supurativa de origem não determinada foram observados. Um animal de um ano de idade (Bovino 11) apresentou emboletamento, decúbito lateral, movimentos de pedalagem, opistótono, paralisia de cauda e ausência dos reflexos corneal, anal e de retirada. Em um animal de dois anos de idade (Bovino 12) observou-se andar cambaleante, dificuldade na apreensão de alimento e decúbito lateral e outro animal de dois anos e meio (Bovino 13) morreu subitamente. Macroscopicamente nos três casos não foram observadas alterações. Na microscopia do Bovino 11 foram observados manguitos perivasculares e vasculite no tronco encefálico (tálamo e colículo). No Bovino12 observaram-se manguitos perivasculares no córtex frontal, parietal, tálamo e colículos, infiltrado mononuclear nas leptomeninges do tálamo, hipocampo e cerebelo, e infiltrado mononuclear no gânglio de Gasser. O Bovino13 apresentou discreto infiltrado mononuclear perivascular no tálamo. Em nenhum destes casos foram realizadas técnicas para diagnóstico de raiva.

Um caso de linfossarcoma foi diagnosticado em bezerro de um ano de idade. O animal apresentava uma debilidade dos membros posteriores que evoluiu para decúbito esternal, com perda dos reflexos de retirada dos membros posteriores. Na necropsia observou-se uma massa de coloração acinzentada, friável e hemorrágica comprimindo a medula entre a terceira e quarta vértebra lombar. $\mathrm{Na}$ histopatologia observou-se massa tumoral compacta composta por células de núcleo pequeno arredondado com citoplasma escasso. Na medula observouse degeneração vacuolar da substância branca.

\section{DISCUSSÃO}

Neste trabalho $34 \%$ dos bovinos necropsiados apresentaram sinais clínicos de alterações neurológicas, o que demonstra a importância das enfermidades do SN como causa de mortalidade na região. Valores maiores foram observados em um estudo realizado no Mato Grosso do Sul, onde de 996 bovinos 47\% apresentaram enfermidades do SN (Lemos et al. 1998), enquanto que em um estudo realizado no Rio Grande do Sul, as doenças do sistema nervoso corresponderam a $10 \%$ das enfermidades diagnosticadas em bovinos (Sanches et al. 2000).

As enfermidades mais freqüentes foram raiva, abscessos no SN, febre catarral maligna e botulismo. A freqüência da raiva em bovinos na região semiárida é alta, sendo a principal doença do SN (Lima et al. 2005). Em 80\% dos casos de raiva foi possível observar a presença de corpúsculos de Negri, número elevado quando comparado a 
estudos realizados no Rio Grande do Sul, onde em $68 \%$ dos casos foi possível a observação dos corpúsculos (Langohr et al. 2003). Nos anos de 2003 e 2007 observou-se maior número de casos, justificado pela ciclicidade da raiva rural que acomete bovinos com periodicidade de até 7 anos (Mori et al. 2004). Aproximadamente $48 \%$ dos casos diagnosticados com sintomatologia nervosa foram de raiva, chamando a atenção para a necessidade da vacinação sistemática dos rebanhos nas áreas endêmicas e o controle das populações de morcegos hematófagos (Mori et al. 2004).

Neste estudo a ocorrência de abscessos no SN se destaca pela sua alta freqüência. Em três casos ocorreram lesões do SN secundárias a corpos estranhos no retículo e ou pericárdio, doença freqüente no semiárido associada ocasionalmente ao fornecimento de cama de frango que além de provocar problemas como o botulismo, veicula corpos estranhos perfurantes. $\mathrm{O}$ acesso dos animais a lixões também favorecem a ocorrência de reticulite traumática. Os casos de abscessos da hipófise também podem está correlacionados com falhas de manejo no momento do desmame, pois em dois animais havia relato de uso de "tabuleta" de desmame e lesões perfurantes na região das narinas. Casos semelhantes foram descritos em bezerros no Rio Grande do Sul que desenvolveram uma doença conhecida como síndrome do abscesso pituitário (Fernandes et al. 2000, Loretti et al. 2003).

A FCM é também uma doença freqüente no Nordeste. A freqüência da enfermidade foi de $6,3 \%$, número superior aos $3,28 \%$ dos diagnósticos realizados em bovinos no Sul do Brasil (Sanches et al. 2000). A diferença na incidência da doença entre o Nordeste e o Rio Grande do Sul pode ser explicada pelo maior contato entre ovinos e bovinos no Nordeste (Macêdo et al. 2007). A única medida possível para profilaxia da enfermidade é manter os bovinos separados dos ovinos, o que nem sempre é possível nas condições do semiárido nordestino (Riet-Correa et al. 2003).

Os diagnósticos de botulismo foram realizados com base no quadro clínico e epidemiologia e na ausência de lesões (Dutra et al. 2001, 2005). A principal causa de botulismo foi à ingestão de cama de frango, diferente do que foi observado por Lemos (2005) onde a principal causa de botulismo foi a osteofagia. A intoxicação botulínica é uma importante causa de mortalidade bovina na pecuária extensiva (Dutra et al. 2005). O Ministério da Agricultura do Brasil proíbe a utilização da cama de frango na alimentação de bovinos, entretanto, seu uso como alimento tem sido uma prática comum nos períodos de escassez de pastagens (Riet-Correa et al. 2003). A não ocorrência de botulismo associado à osteofagia deve-se, provavelmente, à carência de fósforo, e portanto a osteofagia, no semiárido é bem menos grave que em outras regiões do Brasil, principalmente as áreas de Cerrado e a região Norte (Riet-Correa 2007a).

Em relação à ocorrência de doenças tóxicas identificou-se apenas a intoxicação por vagens de Prosopis juli- flora e, mesmo assim, o número de casos foi pequeno considerando a quantidade da planta presente na região e sua utilização como alimento na época de escassez de forragens. Surtos de intoxicação foram descritos na região na década de 90 e trabalhos de pesquisas foram desenvolvidos e práticas racionais de utilização da algaroba foram sugeridas, o que provavelmente reduziu a ocorrência de casos. Além disso, o reconhecimento precoce da enfermidade pelos produtores permite que 0 abate do animal seja realizado a tempo de evitar mortes e perdas econômicas. Recomenda-se que sua utilização na dieta diária não ultrapasse $30 \%$ por no máximo 6 meses. Nos animais a campo, esses não devem permanecer mais de 60 dias em áreas com algaroba. Vagens de algaroba também podem ser utilizadas em animais de engorda na fase de terminação (Riet-Correa et al. 2003, Câmara et al. 2009).

A polioencefalomalacia foi diagnosticada em dois casos. A época de ocorrência da enfermidade coincide com a época de escassez de pastagens e suplementação alimentar, o que sugere alteração na dieta dos animais. Vários fatores podem estar associados ao aparecimento da PEM, alterações no metabolismo da tiamina associada a dietas ricas em concentrado, ingestão de análogos da tiamina, ingestão de vegetais contendo tiaminases, intoxicação por enxofre, chumbo e privação de água e/ou intoxicação por cloreto de sódio (Lemos \& Riet-Correa 2007, Nakazato et al. 2000). Três casos de tuberculose com comprometimento do SNC foram diagnosticados. Além de lesões no SNC, pulmão, rim e linfonodos foram afetados também. A tuberculose é uma enfermidade de grande importância para a saúde pública, visto que a presença da doença em rebanhos bovinos traduz risco iminente à saúde humana (Salazar \& Guimarães 2006). Lesões de tuberculose no SNC ocorrem em animais que adquirem a infecção pela via congênita (Barros et al. 2006).

Três casos com lesões características de meningoencefalite por herpesvírus bovino- 5 foram diagnosticados em bovinos com idade entre 18 e 24 meses de idade. A evolução clínica e as lesões macroscópicas e microscópicas são semelhantes às descritas por outros autores (Elias et al. 2004, Rissi et al. 2006, 2007). A doença pode aparecer em casos esporádicos, como nos casos descritos neste trabalho, ou em forma de surtos que podem afetar até $30 \%$ do rebanho. Bovinos jovens de 6-7 meses são mais afetados, mas esporadicamente a doença pode afetar bezerros lactantes ou animais adultos maiores de 3 anos de idade (Halfen \& Riet-Correa 2007).

Cinco casos de malformações congênitas foram diagnosticados. As malformações congênitas podem estar associadas a defeitos hereditários, agentes teratogênicos, de natureza infecciosa (como vírus), deficiência nutricional e toxinas de plantas (Barros et al. 2006). No semiárido do Nordeste Mimosa tenuiflora e provavelmente Mimosa ophthalmocentra causam malformações em caprinos, ovinos e bovinos, caracterizadas por flexão de membros torácicos (artrogripose) que também podem estar encur- 
tados ou torcidos, micrognatia, fendas palatinas primárias (lábio leporino) e secundárias (palatosquise) e malformações na coluna vertebral (cifose, escoliose, torcicolo ou hiperlordose). Pode ocorrer o nascimento de animais cegos e com acefalia, bicefalia, hidranencefalia, hipoplasia da língua, meningocele e siringocele (Pimentel et al. 2007, Riet-Correa 2007b, Riet-Correa \& Mendes 2007).

Um caso de encefalite tromboembólica foi diagnosticado. Nesse caso as lesões são semelhantes às produzidas por Histophilus somni (Haemophilus somnus). Um caso semelhante foi diagnosticado no Mato Grosso do Sul (Lemos 2005). Essa bactéria é uma importante patógeno que pode causar doença respiratória, meningoencefalite trombótica, artrite e distúrbios reprodutivos. Scarcelli et al. (2004) isolou pela primeira vez a H. somni no Brasil de abortos em bovinos evidenciando a presença desse agente no Brasil.

Outras doenças foram diagnosticadas com menor freqüência, evidenciando que as perdas causadas por essas enfermidades não são significativas, mas devem ser consideradas como diagnósticos diferencias para as outras enfermidades do SN.Em nenhum dos casos foram observadas lesões que pudessem ser interpretadas como sendo sugestivas de encefalopatia espongiforme bovina, evidenciando que na região do semiárido nordestino não ocorre a BSE (Wells et al. 1987).

Agradecimentos.- Este trabalho foi financiado pelo Programa de Apoio a Núcleos de Excelência (Pronex, Proc.001/04, CNPq, FAPESQ, MCT), pelo programa Institutos do Milênio (Proc. CNPq 420012/2005-2) e pelo Instituto Nacional de Ciência e Tecnologia Para o Controle das Intoxicações por Plantas (CNPq, Proc.573534/2008-0). O primeiro autor agradece ao CNPQ e a CAPES pela concessão de bolsas de iniciação científica e de mestrado respectivamente. Aos Professores Claudio S.L. Barros e David Driemeier pela realização da imuno-histoquímica.

\section{REFERÊNCIAS}

Barros C.S.L., Driemeier D., Dutra I.S. \& Lemos R.A.A. 2006. Doenças do Sistema Nervoso de Bovinos no Brasil. Vallée, Montes Claros, MG, p.3-150.

Batista J.S., Riet-Correa F., Teixeira M.M.G., Madruga C.R., Simões S.V.D. \& Maia T.F. 2007. Trypanosomiasis by Trypanosoma vivax in cattle in the Brazilian semiarid: Description of an outbreak and lesions in the nervous system. Vet. Parasitol. 143:174-181.

Batista J.S., Bezerra F.S., Lira R.A., Carvalho J.R.G., Neto A.M.R., Petri A.A. \& Teixeira M.M.G. 2008. Aspectos clínicos, epidemiológicos e patológicos da infecção natural em bovinos por Trypanosoma vivax na Paraíba. Pesq. Vet. Bras. 28(1):63-69.

Câmara A.C.L., Costa N.A., Riet-Correa F., Afonso J.A.B., Dantas A.F. M., Mendonça C.L. \& Souza M.I. 2009. Intoxicação espontânea por vagens de Prosopis juliflora (Leg. Mimosoideae) em bovinos em Pernambuco. Pesq. Vet. Bras. 29(3):233-240.

Dutra I.S. 2001. Epidemiologia, quadro clínico e diagnóstico pelo soro neutralização em camundongos do botulismo em bovinos no Brasil, 1989-2000. Tese de Livre-Docência, Curso de Medicina Veterinária, Universidade Estadual Paulista, Campus de Araçatuba. 133p.

Dutra I.S., Döbereiner J., Rosa I.V., Souza L.A.A. \& Nonato M. 2001. Surtos de botulismo em bovinos no Brasil associados à ingestão de água contaminada. Pesq. Vet. Bras. 21(2):43-48.

Dutra I.S., Döbereiner J. \& Sousa A.M. 2005. Botulismo em bovinos de corte e leite alimentados com cama de frango. Pesq. Vet. Bras. 25(2):115-119.

Elias F., Schild A.L. \& Riet-Correa F. 2004. Meningoencefalite e encefalomalacia por Herpesvírus bovino-5: distribuição das lesões no sistema nervoso central de bovinos naturalmente infectados. Pesq. Vet. Bras. 24(3):123-131.

Fernandes C.G., Riet-Correa F., Schild A.L., Bailardi C. \& Stigger A. 2000. Pituitary abscesses in young calves associated with the use of a controlled suckling devise. J. Vet. Diag. Invest. 12:70-71.

Guedes K.M.R., Schild A.L., Riet-Correa F., Barros S.S. \& Simões V.D.S. 2006. Degeneração esponjosa no sistema nervoso central de bezerros da raça Sindhi. Pesq. Vet. Bras. 26(3):157-160.

Halfen D.C. \& Riet-Correa F. 2007. Infecção por Herpesvírus Bovino-1 e Herpesvírus Bovino-5, p.126-137. In: Riet-Correa F., Schild A.L., Lemos R.A.A. \& Borges J.R.J. (Eds), Doenças de Ruminantes e Eqüídeos. Vol.1. $3^{\mathrm{a}}$ ed. Pallotti, Santa Maria, RS.

Langohr I.M., Irigoyen L.F., Lemos R.A.A. \& Barros C.S.L. 2003. Aspectos epidemiológicos, clínicos e distribuição das lesões histológicas no encéfalo de bovinos com raiva. Ciência Rural 33(1):125-131.

Lemos R.A.A., Brum K.B., Bernado K.C., Katayama K.A., Bonilha M.M. \& Cavallero J.C.M. 1998. Aspectos epidemiológicos das principais enfermidades caracterizadas por sintomatologia nervosa em bovinos, diagnosticadas no Mato Grosso do Sul. Universidade Federal de Mato Grosso do Sul, Campo Grande. Relatório de Bolsa de Iniciação Científica do CNPq. 16p.

Lemos R.A.A. 2005. Enfermidades do sistema nervoso de bovinos de corte das regiões Centro-oeste e Sudeste do Brasil. Tese de Doutorado, Universidade Estadual Paulista "Julio de Mesquita Filho", Jaboticabal. 149p.

Lemos R.A.A. \& Riet-Correa F. 2007. Poliencefalomalacia, p.658-670. In: Riet-Correa F., Schild A.L., Lemos R.A.A. \& Borges J.R.J. (Eds), Doenças de Ruminantes e Eqüídeos. Vol.2. $3^{\text {a }}$ ed. Pallotti, Santa Maria.

Lima E.F., Riet-Correa F., Castro R.S., Gomes A.B. \& Lima F.S. 2005. Sinais clínicos, distribuição das lesões no sistema nervosos e epidemiologia da raiva em herbívoros na região Nordeste do Brasil. Pesq. Vet. Bras. 25(4):250-264.

Loretti A., Ilha R.S., Riet-Correa G., Driemeier D., Colodel E.M. \& Barros C.S.L. 2003. Síndrome do abscesso pituitário em bezerros associados ao uso de tabuleta nasal de desmame interrompido. Pesq. Vet. Bras. 23(1):39-46.

Macêdo J.T.S.A., Riet-Correa F., Simões S.V.D., Dantas A.F.M. \& Nobre V.M.T. 2007 Febre catarral maligna em bovinos na Paraíba. Pesq. Vet. Bras. 27(7):277-281.

Mori A.E., Lemos R.A.A. \& Kadri A. 2004. Raiva, p.63-86. In: Lemos R.A.A., Mori A.E., Kadri A. \& Katayama K.A. (Eds), Botulismo, meningoencefalite por herpesvírus bovino tipo 5, polioencefalomalacia, raiva. Série Qualificação Rural 2, Ed. UFMS, Campo Grande, MS.

Nakazato L., Lemos R.A.A. \& Riet-Correa F. 2000. Polioencefalomalacia em bovinos nos estados de Mato Grosso do Sul e São Paulo. Pesq. Vet. Bras. 20(3):119-125.

Pimentel L.A., Riet-Correa F., Gardner D., Panter K.E., Dantas A.F.M., Medeiros R.M.T., Mota R.A. \& Araujo J.A.S. 2007. Mimosa tenuiflora as a cause of malformations in ruminants in the northeastern Brazilian semiarid rangelands. Vet. Pathol. 44:928-931.

Riet-Correa F., Tabosa I.M., Azevedo E.O., Medeiros R.M., Simões S.V. D., Dantas A.F.M., Alves C.J., Nobre V.M.T., Athayde A.C., Gomes A.A. \& Lima E.F. 2003. Doença dos ruminantes e eqüídeos no Semiárido da Paraíba. Semi-Árido em Foco 1:4-111.

Riet-Correa F. 2007a. Suplementação mineral em ruminantes, p.263280. In: Riet-Correa F., Schild A.L., Lemos R.A.A. \& Borges J.R. (Eds), Doenças de Ruminantes e Eqüídeos.Vol.2. $3^{\underline{a}}$ ed. Pallotti, Santa Maria, RS. 
Riet-Correa F. 2007b. Plantas tóxicas e micotoxinas que afetam a reprodução em ruminantes e eqüinos no Brasil. Biológico, São Paulo, 69(2):63-68.

Riet-Correa F. \& Mendez M.C. 2007. Intoxicação por plantas e micotoxinas, p.99-221. In: Riet-Correa F., Schild A.L., Lemos R.A.A. \& Borges J.R.J. (Eds), Doenças de Ruminantes e Eqüídeos.Vol.2. 3aㅡ ed. Pallotti, Santa Maria, RS. 694p.

Rissi D.R., Oliveira F.N., Rech R.R., Pierezan F., Lemos R.A.A. \& Barros C.S.L. 2006. Epidemiologia, sinais clínicos e distribuição das lesões encefálicas em bovinos afetados por meningoencefalite por herpesvírus bovino-5. Pesq. Vet. Bras. 26(2):123-132.

Rissi D.R., Rech R.R., Flores E.F., Kommers G.D. \& Barros C.S.L. 2007. Meningoencefalite por herpesvírus bovino-5. Pesq. Vet. Bras. 27(7):251-260.

Salazar F.H.P. \& Guimarães E.B. 2006. Tuberculose bovina, p.59-112.
In: Lemos R.A.A. (Ed.), Brucelose Bovina, Tuberculose Bovina. Série Qualificação Rural 4. Ed. UFMS, Campo Grande, MS. 112p.

Sanches A.W.D., Langohr I.M., Stigger A.L. \& Barros C.S.L. 2000. Doenças do sistema nervoso central em bovinos no sul do Brasil. Pesq. Vet. Bras. 20(3):113-118.

Scarcelli E., Genovez M.E., Cardos M.V., Campos F.R., Miyashiro S., Piatii R.M., Teixeira S.R., Stefano E., Okuda L.H. \& Pituco E.M. 2004. Abortamento e morte embrionária em receptoras bovinas por Histophilus somni (Haemophilus somnus). Acta Scientiae Veterinariae 32(1):59-64.

Wells G.A.H., Scotta C., Johnson C.T., Gunning R.F., Hancock R.D., Jefrey M., Dawson M. \& Bradley R. 1987. A novel progressive spongiforme encephalopathy in cattle. Vet. Rec. 121:419-420.

Will R.G., Ironside J.W., Zeildler M., Cousens S.N., Estibeiro K., Alpeovitch A., Poser S., Pocchiari M., Hofman S. \& Smith P.G. 1996. A new variant of Creutzfeldt-Jakob disease in the UK. Lancet 347:921-925. 